\title{
ACERCA DE IDENTIDADES, GLOBALIDADES Y FRAGMENTOS: UNA CONVERSACIÓN CON FREDRIC JAMESON
}

POR

\author{
Aristides Escobar Argaña \\ Montclair State University
}

ARISTIDES EsCoBAR: El llamado postmodernismo nombra un presente marcado por la sociedad pos-industrial, un espacio dominado por las informaciones, un tiempo cibernetizado. En este contexto, sería interesante preguntarse qué pasa con sociedades, como las latinoamericanas, que acceden a ese tiempo desde modernidades incompletas y fragmentadas, desde experiencias ni siquiera enriquecidas con aportes ilustrados y conquistas tecnológicas. ¿No significará la recepción de la postmodernidad la contracara de una nueva imposición poscolonial, una manera de pensar gestada desde lo hegemónico? Desde este punto de vista, ¿no podría, lo posmoderno latinoamericano constituir nada más que un conjunto de manifestaciones reflejas de un centro fundacional de sentido?

FREDRIC JAMESON: Para responder a estas preguntas es crucial manejar un concepto tal como el de desarrollo disparejo. Histórica y cronológicamente hablando, existen varios niveles de modernización que se sobreponen y que hacen imposible nombrar la existencia de un modelo modernizador de desarrollo igual y parejo, aunque éste haya sido el propósito de los países del primer mundo. Lo que ocurre, es que en el contexto de este sistema mundial globalizador ningún país podría escapar del fenómeno que llamamos postmodernismo. Ahora bien, en la dinámica de tal fenómeno pueden intercalarse lo que tú llamas "formas incompletas de modernismo" y momentos aun más primitivos, como los pertenecientes a sistemas feudales y formas indígenas premodernas. Estos coexisten en América Latina donde constituyen, si no una síntesis, sí relaciones específicas nacionales dentro de una estructura que puede variar de país en país. Algunas de estas relaciones devienen dominantes; otras subordinadas. Sin embargo, la cuestión de las culturas primitivas puede también prestarse a confusiones: por ejemplo, los aborígenes australianos tienen videocaseteras y videos cuyas imágenes han sabido incorporar los códigos de sus culturas y estilos de vida. Este hecho cultural invita a concebir esta incorporación tecnológica no como una homogeneización masiva sino más bien como una entrada dispareja que arrastra diferentes elementos. Por otro lado, pienso que es importante puntualizar el hecho que los Estados Unidos de América — quizá uno de los países capitalistas más avanzados del mundo, en donde ni siquiera existió un pasado feudal - también presenta síntomas de una modernización desigual. Tomemos como ejemplo el caso de las maquiladoras en grandes ciudades como en Los Angeles. Éstas son fábricas donde la situación humana de los trabajadores, en su mayoría inmigrantes ilegales del sexo femenino, se acerca más al modelo 
de explotación laboral del siglo XIX que al del XX. Este modelo coexiste con formas de desarrollo más avanzado en una peculiar combinación de fuerzas, tendencias y elementos.

A.E.: La modernidad no ha cumplido con sus promesas de salvar el mundo; estamos viviendo por eso una época marcada por el desgano, por el descreimiento de los viejos sueños modernos; existe una renuncia postmoderna a creer en una transformación del mundo, a ver una cierta esperanza de desarrollo y a construir un sentido colectivo. Pero por otra, es importante reconstruir conjuntos, reimaginar unfuturo, proponer modelos más equitativos, ¿Cómo replantear hoy la utopía?

F.J.: No sé si hoy es posible hablar de utopías como lo hacíamos hace dos décadas. Pero este tremendo entusiasmo por las computadoras y por las ventajas que la Internet puede ofrecer, así como la misma noción de espacio cibernético, son formas actuales de fantasías utópicas. Si bien no es común que las mismas sean activadas políticamente, tenemos el caso de los zapatistas que se han valido de la Internet dentro del marco de sus actividades políticas. Así como el caso iraní - la primera revolución postmoderna, según mi punto de vista- en donde el Ayatolah transmitía sus sermones y discursos políticos por medios audio-visuales de radio y televisión. Existen, por lo tanto, nuevas formas políticas que emergen de la postmodernidad y existen, también, estas utopías sintomáticas que yo me inclinaría a leer como proyecciones fantásticas en una situación en donde las acciones políticas colectivas realizables parecerían imposibles.

A.E.: Es observable hoy una emergencia de nuevos fundamentalismos nacionalistas, caso Bosnia p.e. Este hecho parecería constituir un mentís a las proclamas postmodernas

F.J.: En referencia a lo que hoy día se llama nacionalismos, bueno, creo que este concepto ya no es válido. Considero que la situación yugoeslava y la del fundamentalismo islámico, constituyen movimientos postmodernos ya que los mismos no provienen de una tradición histórica derivada de antiguas rivalidades que, como en el caso de los croatas y serbios, se remontan a la Edad Media. Creo, pues, que son invenciones del presente, no tradiciones que sobreviven. De hecho, muchos historiadores están considerando que ciertas tradiciones son más bien construcciones que se hacen desde el presente sobre hechos ocurridos en el pasado. Por eso pienso que algunas visiones e interpretaciones del Islam, por ejemplo, están más bien conectadas con intereses económicos y políticos de estructuras de poder; lo mismo se podría decir del caso de Bosnia. Esto nos permite ver la cuestión de las identidades políticas desde una nueva perspectiva; así, mientras que en algunos países, que no han tenido la oportunidad de reivindicar sus luchas, las identidades políticas adquieren un sentido emancipatorio, en otros países, impulsada quizá por factores externos, la cuestión se torna sangrienta. Pero creo que aquí estamos todavía en presencia del proceso de descentralización del poder de la nación: aún la mayor y más antigua unidad colectiva. Aunque en el contexto de la globalización transnacional se hable hoy de la desaparición del Estado, creo prudente señalar que la nación tiene aún una función muy importante: la del control del ámbito laboral. Buen ejemplo es el caso de Inglaterra, cuya retórica oficial incita a los obreros a no reclamar aumentos salariales, a reducir sus actividades sindicales, a no declararse en huelga, etc., para beneficiar así la producción inglesa y asegurar su hegemonía en la competencia del mercado internacional. Yo creo que este discurso, propio de los gobiernos neoliberales, hace eco en todo el mundo actual. Aunque el neoliberalismo 
propague e imponga ideológicamente el libre comercio y la descentralización del mercado, esto no significa que anule el Estado: éste tiene una marcada presencia que se manifiesta en el control del mercado nacional e internacional.

A.E.: En cierto sentido, la crítica a la modernidad es una crítica a las totalidades, las perspectivas de conjunto y a los intentos de representar el mundo en una sola imagen y a través de un sólo discurso. Pero desde esta misma crítica se comenzó a hablar de fragmentaciones, se empezó a hablar de lo otro, de alteridades y diferencias. ¿Cómo congeniar ambas posiciones? ¿Cómo conciliar las ideas de globalización, por un lado, y diferencia multicultural, por otro?

F.J.: El ataque a la totalización es uno de los temas favoritos del pensamiento actual. Sin embargo, esta impugnación se encuentra basada, la mayor de las veces, en un malentendido acerca de lo que, filosóficamente, el concepto de totalización significa. Lo que es importante retener cuando pensamos en lo totalitario es que no somos nosotros los que teorizamos sobre la totalización, quienes imponemos este proceso, sino que es el capitalismo mismo quien lo hace. Por lo tanto la crítica antitotalitaria debe ir dirigida contra el capitalismo transnacional y no contra los pensadores que analizan el fenómeno como parte de un proceso histórico progresivamente unificado. Ahora, en relación a este punto yo agregaría una reflexión: la idea de totalización como una pretensión cognoscitiva total de la realidad es una ilusión. Yo creo que la doctrina de la totalización trae consigo la imposibilidad de su representación. Lukacs habla de la pulsión, del impulso a una totalización sugiriendo una imposiblidad de cumplimiento, razón por la cual, creo, toda discusión sobre la totalidad debería incluir la cuestión de la representación. Probablemente el mundo nunca fue representable; aun en las formas más simples de organización social, en las sociedades tribales, existió siempre un ámbito inabarcable y sobrenatural representado desde lo religioso. Yo creo que ésta es una imposibilidad histórica de la que no escapan la postmodernidad y la globalización actual, aunque hoy esta imposibilidad sea históricamente distinta y nos ubique dentro de una problemática peculiar. Yo trato de desarrollar en algunos de mis libros un concepto, difícil de traducir, al que podríamos quizá llamar "cartografía cognoscitiva": el mismo describe un esfuerzo por representar una imagen total de la realidad e incluye también la imposibilidad última de tal pretensión. En este nuevo sistema mundial, el problema se agudiza y da lugar a una serie de alegorías de totalidad. Pienso que el entusiasmo de la gente que está en la informática, en el mundo de la Internet, el correo electrónico, etc., los lleva a creer en una posesión real de totalidad, sin embargo, yo creo que es ésta sólo una representación alegórica de la misma por cuanto que ningún individuo biológico podría ser capaz de asir la totalidad de la realidad. Antiguamente existían figuras como la del emperador o la de ciertos dictadores absolutos, formas antropomórficas en las cuales la gente creía ver la totalidad de una estructura; visión ésta también falsa ya que el problema de la representación es relativamente reciente y deriva precisamente de esta dificultad que tenemos de ubicarnos como sujetos en una inmensa e inabarcable realidad. Ahora, tú hablas de la otredad y ése es también un concepto bien paradójico: dentro de una diálectica hegeliana eventualmente cuando invocamos a la identidad terminamos invocando a la diferencia pero cuando invocamos a la diferencia, también invocamos a la identidad. Cuando hablamos de una identidad específica nos referimos a la diferencia de esa identidad con otras identidades y cuando estamos hablando de la diferencia estamos hablando de su 
especificidad que a la vez cobra una identidad en sí. No es casual, por lo tanto, que en los Estados Unidos, por nombrar un ejemplo, la política de la diferencia sea, a su vez, una política de identidad; dentro de esa coyuntura el desarrollo de la política de la diferencia fue sólo posible debido al incremento de las distintas identidades. Algunos grupos, percibidos como radicalmente diferentes, no lograron articular una política de identidad. Este es el caso del movimiento negro en los Estados Unidos, donde el surgimiento y fortalecimiento de una clase media de color con mayor protagonismo en los medios masivos de comunicación, hizo que el blanco comenzara a dejar de percibir la diferencia de ésta y, así, a no reconocerle su diferencia. Este hecho es complejo en cuanto implica conciliar la diferenciación de las identidades con el movimiento de globalización que empuja a una nueva homogeneidad producida por la tecnología. Paradójicamente, esta estandarización mundial da lugar al surgimiento de una serie de identidades nuevas, por lo que la "otredad" funciona como un concepto dialéctico y ambivalente, casi extraño. Lo que sí es crucial dentro de este concepto es que el Otro habla, tiene una voz propia, cuenta su verdad y su historia conquistando así una participación desde su diferencia. Aquí cabe una salvedad: es importante respetar esa diferencia pero no absolutizarla como algo radicalmente ajeno a nosotros, pues en esa postura descansan el sexismo, el racismo, la homofobia, etc.

A.E.: ¿Ocupa siempre el otro una posición subalterna?

F.J.: Basada en ideas de Gramsci, la noción del subalterno es un tanto diferente. Pienso que la subalternidad es un estado mental, es un complejo de inferioridad colectivo que ha sido inoculado por la estructura de poder a grupos minoritarios, durante varias generaciones a veces.

A.E.: ¿Puede explicarse este hecho comoprovocado por una introyección de la norma por parte del subalterno?

F.J.: Exactamente, y se expresa en hábitos de obedencia, respeto, autonegación de la subjetividad, etc. Una figura importante en el desarrollo de este concepto gramsciano fue Fanon, quien produjo un gran escándalo con una teoría que sostiene la subalternidad. Yo interpreto que él quiso significar que el subalterno tiene que ser capaz de inferir miedo al dominador y, a partir de este hecho, reconocerse como igual y superar su condición inferior. Pienso que la noción de subalternidad es muy importante; su superación exige una práctica colectiva conducente a desmantelar estructuras obsoletas que promueven la inferioridad. Es algo así como la toma del poder psíquico por parte de la colectividad.

A.E.: Al margen de un centro blanco, masculino, heterosexual y occidental, se afirman grupos emergentes, como los constituidos por mujeres, minorías sexuales, minorías étnicas y movimientos sociales. Estos grupos suponen, en cierto sentido, identidades fracturadas, con respecto a aquel centro. ¿Qué posibilidades tienen de no disolverse como microidentidades y de intervenir activamente en la trama del tejido de la sociedad civil?

F.J.: Antes que nada es preciso destacar un hecho: el mercado valora estos sectores, éstos son nuevos grupos de mercado cuyas identidades son rescatadas en cuanto puedan generar provecho económico al sistema capitalista. Ahora bien, opino que tales grupos construyen sus identidades en la oposición que puedan ejercer contra otros grupos. Si carecen de un adversario contra quien levantar su voz, contra quien reafirmarse en su diferencia, es muy difícil que mantengan su cohesión y que sobrevivan. Es por eso que es 
mucho más fácil que estos grupos se formalicen y adquieran cohesión durante regímenes autoritarios que durante tiempos políticos más permisivos. En cuanto al concepto de sociedad civil, yo tengo mis reservas; pienso que es un concepto burgués ligado a la idea de mercado. Una importante manera de canalizar sus reivindicaciones y concertaciones pasa por el lobby. Aunque no creo que esta institución en sí sea perniciosa -reconozco su validez para ciertas negociaciones - me preocupa en cuanto se aparta de la idea colectiva de frentes amplios de lucha. Yo creo que los diferentes grupos identitarios de países que están emergiendo de regímenes monolíticos y totalitarios lograrán mayor eficacia política en torno a alianzas de grupos menores y no enclaustrados en la individualidad de compartimientos estancos. Esta problemática ha sido teorizada por Laclau, con quien personalmente no estoy de acuerdo en sus análisis sobre el socialismo y el marxismo, pero pienso que él ha aportado un sobresaliente modelo formal según el cual las alianzas políticas toman lugar y se hacen efectivas. Por mi parte, creo que tiene que existir siempre una meta política y colectiva de mayor alcance: la transformación del sistema.

El desarrollo de la política debe en la actualidad articularse desde dos registros: uno, el de las reivindicaciones individuales por medio de las organizaciones de base; y el otro, provisto de una perspectiva de conjunto, debe apuntar a una transformación social. Me temo que lo que ocurre a la mayoría de los grupos identitarios es que vacilan entre seguir operando a nivel de lobby u optar por una política más amplia de alianzas; parecería ser que estos grupos carecen de una visión política de transformación social, optando por permanecer dentro del sistema, aislados los unos de los otros, por miedo a diluirse en otros grupos o a perder especificidad en sus demandas.

T.E.: Uno de los temas más importantes de la posmodernidad se relaciona con el cuestionamiento a la dialéctica. El principio básico de la modernidad es que existe una Idea que se va desplegando y superando a través de contradicciones, cada una de las cuales implica la superación enriquecedora de la anterior hasta arribar a una sintesis que niega, transforma y redime a los momentos previos y supone una instancia superior. Este movimiento está prefijado por una suerte de guión de la historia; una historia provista, entonces, de una meta y un sentido. Esta concepción teleológica de la historia se rompe con la posmodernidad: ya no existe una contradicción fundante y esencial sino pequeños enfrentamientos que se juegan a varios niveles y que avanzan ramificadamente. Y ya no es posible hablar de un futuro predecible en estos términos: hay muchos conflictos que quedan sin sintetizar y muchos procesos cuyo desenlace se desconoce. En este paisaje incierto aparecen nuevos sujetos, como las identidades gay, definidos no a partir de una oposición centrada en los modos de producción sino en demandas cotidianas y en reivindiciones sectoriales que no siempre se definen a través de conflictos definitivos sino, muchas veces, mediante concertaciones y oposiciones menores. ¿Quisiera comentar algo sobre esto?

F.J.: Sí, la desaparición de la dialéctica es un tema muy discutido en la actualidad. Fersonalmente, creo que la dialéctica no es teleológica en un sentido lineal. Dialécticamente considerada, la lógica histórica de la sociedad se despliega mediante coyunturas y contingencias impredecibles. Pienso que habría que analizar desde esta óptica el movimiento dialéctico, recordando que, si bien no podemos provocar las coyunturas históricas, sí podemos conocer y analizar su dinámica cuando éstas ocurren. El mayo francés por 
ejemplo, fue absolutamente imprevisto por los analistas; evidentemente no se puede prever la historia: sólo se puede entenderla después que haya ocurrido. Lo que sí se puede es producir una acción teleológica; los grupos pueden proyectar un futuro hacia el cual dirigirse comprendiendo que tal tránsito puede ser acelerado o entorpecido por coyunturas históricas y contingencias accidentales imposibles de predecir. Resumiendo, pienso que sería erróneo imaginar la dialéctica —desde una lógica simplista y tradicional-como un despliegue de fuerzas apuntadas linealmente a un futuro; pero creo que la lógica dialéctica tiene un rol que cumplir en la explicación de varios procesos, como el que mencionaba cuando me refería a la problemática de la identidad y la diferencia; estos procesos son dialécticos y no pueden ser explicados por la lógica del empirismo o la de disciplinas como la sociología.

T.E.: Se supone que ya no existe una idea de poder despositada en un centro. Sin embargo, es evidente la vigencia de culturas que son dotadoras de sentido y que marcan pautas ideológicas o referencias políticas muy fuertes. ¿Cómo se plantea, entonces, el lugar del poder? ¿Es posible hablar hoy de una diseminación del poder o ya no existen actualmente culturas centrales y subalternas?

F.J.: Los países que exportan capitales vienen a constituir el centro; la exportación global del capital conforma la hegemonía. Mis amigos de la India se molestan cuando digo que su país pertenece al Tercer Mundo; por cierto aunque aquél sea un país inmenso y aparentemente poderoso, es un estado que sólo importa capital a nivel local. Los Estados Unidos, Japón y Europa occidental son los países del Primer Mundo pues son ellos quienes exportan capital a nivel global convirtiéndose en los centros financieros del mundo. Estamos en una etapa financiera del capitalismo por lo tanto, estos son los detentadores del poder. El tema que debemos abordar es el del regionalismo ya que en muchos países existe una lógica regional. En los Estados Unidos tal lógica ha sido barrida por la estandarización de los medios masivos de comunicación que terminaron anulando las profundas diferencias regionales, como las que distinguían el sur del norte del país.

En otros países, sin embargo, existe todavía cierta vitalidad regional que a veces trae consigo guerras internas pero que también puede significar una fuente de poder. Hoy día se habla del fracaso del comunismo y del capitalismo, pero no se menciona el fracaso del federalismo. Canadá, la Unión Soviética, diseñada al menos utópicamente como un sistema federal, Yugoslavia, que funcionó federalmente con éxito bajo el mando de Tito, y España, encaminada en esa dirección, se encuentran en profundas crisis políticas. Me parece, por lo tanto, que es necesario ubicar dentro de este contexto político cuestiones como la descentralización, la vitalidad del regionalismo, las fuerzas de diferenciación, la producción de nuevas áreas y nuevos grupos, los problemas de fragmentación y autoritarismo; cuestiones todas éstas que afectan a la izquierda y a la derecha tanto en el campo de la religión como en el de la política y que constituyen los síntomas más profundos de la crisis política actual.

T.E.: Asumiendo lo breve de tu estancia en Paraguay, me gustaría escuchar un rápido comentario suyo acerca de cómo ubicaría este país en el contexto de los conceptos que estuvo manejando a lo largo de nuestra conversación.

F.J.: Bueno, como tú bien dices hablo desde mi desconocimiento acerca del Paraguay; voy a aventurar, pues, conclusiones de testimonios aislados y de conversaciones informales 
que entablé con ciertas personas. Déjame comenzar con algunas consideraciones abstractas: me parece que uno de los problemas cruciales del sistema moderno global es el asunto de la autonomía o la ausencia de ella. A partir de esa disyunción podemos identificar regiones o países que tienen una mayor posibilidad autónoma, ya que su dinámica interna no ha sido captada inmediatamente por procesos de globalización. Me han dicho que, fundamentalmente agrícola, este país no ha llegado aún a condiciones urbanas extremas, como es el caso de otros países latinoamericanos e incluso del primer mundo. Pienso que regiones pequeñas como ésta tienen mejores oportunidades de desarrollar una identidad nacional que las grandes naciones federales como Rusia y los Estados Unidos, inmensos mercados ya dominados completamente por fuerzas transnacionales. Estas son, por supuesto, sólo impresiones. 
